\title{
Metabolic Abnormalities in a Cohort of Overweight and Obese Children in an Urban Setting of Sri Lanka
}

\author{
Loretta S. Warnakulasuriya, ${ }^{1}$ Dulani L. Samaranayake, ${ }^{2}$ Adikaram V. N. Adikaram, ${ }^{3}$ \\ Manel M. A. Fernando, ${ }^{4}$ Elisabet Rytter, ${ }^{5}$ Iris Ciba, ${ }^{6,7}$ Peter Bergsten, ${ }^{6,7,8}$ \\ Anders H. Forslund, ${ }^{6,7}$ K. D. Renuka Ruchira Silva, \\ and Vithanage Pujitha Wickramasinghe $\mathbb{B}^{10}$ \\ ${ }^{1}$ Postgraduate Institute of Medicine, University of Colombo, Colombo, Sri Lanka \\ ${ }^{2}$ Department of Community Medicine, University of Colombo, Colombo, Sri Lanka \\ ${ }^{3}$ Health Unit, Bandaranaike International Airport, Katunayake, Sri Lanka \\ ${ }^{4}$ Colombo North Teaching Hospital, Ragama, Sri Lanka \\ ${ }^{5}$ Clinical Nutrition and Metabolism, Department of Public Health and Caring Science, Faculty of Medicine, Uppsala University, \\ Uppsala, Sweden \\ ${ }^{6}$ Department of Women's and Children's Health, Uppsala University, Uppsala, Sweden \\ ${ }^{7}$ Uppsala University Children's Hospital, Uppsala, Sweden \\ ${ }^{8}$ Department of Medical Cell Biology, Uppsala University, Uppsala, Sweden \\ ${ }^{9}$ Department of Applied Nutrition, Wayamba University of Sri Lanka, Makandura, Gonawila, Sri Lanka \\ ${ }^{10}$ Department of Paediatrics, Faculty of Medicine, University of Colombo, Colombo, Sri Lanka
}

Correspondence should be addressed to Vithanage Pujitha Wickramasinghe; pujitha@pdt.cmb.ac.lk

Received 14 March 2021; Revised 24 May 2021; Accepted 21 June 2021; Published 5 July 2021

Academic Editor: GianLuca Colussi

Copyright (c) 2021 Loretta S. Warnakulasuriya et al. This is an open access article distributed under the Creative Commons Attribution License, which permits unrestricted use, distribution, and reproduction in any medium, provided the original work is properly cited.

Childhood obesity-related metabolic derangements are increasing among South Asian populations. Most of these changes persist to adulthood. This study aims to describe the distribution of metabolic abnormalities among 7- to 17-year-old overweight and obese children in the Gampaha District of Sri Lanka. Overweight children (age- and gender-adapted BMI $>+1 S D$, WHO standards) were selected from a community survey carried out in the Negombo Education Zone of Gampaha District. After a 12hour overnight fast, blood was drawn, and blood glucose (FBG), lipid profile, insulin, and liver transaminases were measured. Two hours after a glucose load, blood was drawn for random blood glucose (RBG) and insulin. Metabolic syndrome (MetS) was diagnosed using modified IDF criteria for children. Anthropometry, fat mass (FM), and blood pressure were measured. Hepatic fat pattern was assessed ultrasonically. The data of 403 children ( 210 boys) were analysed. Of the study population, $16.4 \%$ were overweight (BMI for age +1 to $+2 \mathrm{SD}$ ), $72 \%$ were obese (BMI for age $>+2$ to $+3 \mathrm{SD}$ ), and $11.6 \%$ were severely obese (BMI for age $>+3 \mathrm{SD}$ ). Insulin resistance was seen in $46.8 \%$, and prevalence increased with age. Mean postprandial insulin ranged from 368 to $625 \mathrm{pmol} / \mathrm{L}$ and was elevated in 35\%. Dysglycaemia was seen among 20.8\%. MetS was present in 19.8\%, and $84 \%$ had at least one metabolic abnormality. Different degrees of hepatic steatosis were observed in 32.5\%, and elevated ALT/AST ratio was seen in $58 \%$ of the population. Overweight and obesity during childhood were associated with multiple metabolic abnormalities including MetS, and they occur from a young age. It is important to screen children for overweight/obesity early in life and intervene to prevent them from developing metabolic complications. 


\section{Introduction}

Obesity, one of the primary risk factors for noncommunicable diseases (NCDs), is spreading in epidemic proportions all over the world, penetrating rapidly into the paediatric population [1]. The prevalence of obesity has doubled in many countries since 1980 [1]. Although the prevalence of childhood obesity is lower than that of adults, the rate of increase is very high among children compared to adults. Between 1980 and 2015, there was a significant relative increase of $20.0 \%$ in the prevalence of obesity in countries with a low socio-demographic index and the highest rates of increase were observed in countries with a middle socio-demographic index [2]. Although the national rates of childhood obesity are still low in Sri Lanka, there are certain geographical areas, which show increased prevalence. Data from Colombo municipal area showed overweight and obesity to be about $14 \%$ among 8 - to 12 -year-old school children [3] and in Colombo district about 13\% among 5- to 15-year-old children [4]. In the Negombo education zone, overnutrition was shown to vary between 10 and $18 \%$ across 5-15 year age group with the prevalence increasing with age [5].

The epidemic of obesity and its related comorbidities have adversely impacted children and adolescents all over the world. Childhood obesity is a major risk factor for the development of adult obesity and many NCDs such as diabetes, hypertension, dyslipidaemia, and some forms of cancer later in life [6]. Total body fat mass (FM) of Sri Lankan children is high compared to children of other parts of the world [7] and a similar rise is seen in insulin resistance [8]. These two factors could be the reason for the high prevalence of obesity-related metabolic complications among Sri Lankan children [4]. Severity of childhood obesity scales up the magnitude of metabolic problems. Greater the severity of obesity, higher the risk of developing atherosclerosis, hypertension, dysglycaemia, type 2 diabetes, metabolic syndrome, fatty liver disease, and premature death [9]. Obese children also have lower self-esteem, poor social functioning, and internalising behaviour problems compared with their non-overweight peers. Even quality of life could be poor and comparable to a child with malignancy [10].

Two main obesity-related abnormalities that have long-lasting consequences are cardiovascular diseases, and nonalcoholic fatty liver disease [11]. The Bogalusa heart study showed that children with severe obesity had a 2.7-fold greater risk of developing hypertension compared to their moderately obese counterparts [12]. Six cardiovascular risk factors were evaluated in this cohort of school children: low-density lipoprotein, triglycerides, high-density lipoprotein, cholesterol, fasting insulin, and systolic and diastolic blood pressure. This evaluation demonstrated that $39 \%$ of children with moderate obesity and $59 \%$ of children with severe obesity had at least two cardiovascular risk factors [12].

The spectrum of nonalcoholic fatty liver disease ranges from reversible hepatic macrovascular steatosis without inflammation to irreversible fibrosis and cirrhosis [13]. It is considered to be the commonest liver disease in children at present. It is documented that NAFLD prevalence varies from $3 \%$ among the general population of children to $80 \%$ in obese children [14]. Furthermore, in children, NAFLD is commonly seen among males during puberty and is associated with insulin resistance [15]. A Sri Lankan study estimated the presumed NASH to be about $18 \%$ among obese children [16]. Most of the children with NAFLD are asymptomatic or have nonspecific symptoms such as vague abdominal pain. The gold standard of diagnosis is liver biopsy, but it is invasive. In the absence of specific biochemical tests, elevated ALT/AST ratio $>1$ is suggestive of NASH [17]. Ultrasound scan (USS) is used to screen for NAFLD and has a predictive value of $84-94 \%$ [18]. A recent large prospective paediatric cohort showed a good correlation between steatosis score assessed by USS and the severity of steatosis on liver biopsy [19]. However, a recently developed transient elsastography (FibroScan ${ }^{\circledR}$ ) and ultrasound eleastography using $2 \mathrm{D}$ shear wave elestography and point shear wave elastograpy can detect liver fibrosis and fatty liver noninvasively in both children and adults [20]. However, these equipments are not freely available in resource-poor settings and each scan is also costly. Further studies have shown that ultrasound scan used with standardized scoring in children does not differ from results obtained by FirbroScan ${ }^{\circledR}$ [21] Therefore, in the absence of a liver biopsy, a combination of steatosis detected by USS and an ALT/AST $>1$ is a reasonable tool to diagnose NASH in a resource-poor setting.

Sex differences in obesity and related metabolic abnormalities have been highlighted in several studies [22]. The mechanism underlying the sex differences in cardiovascular risk factors (CVRF) is not clearly understood. Factors such as hormonal milieu influenced by fat content and gonadal maturity [23], X-chromosome dosage [24], genes of obesity and lipid metabolism largely drive the occurrence of childhood MetS [25].

As incidence of obesity is increasing and also insulin resistance and metabolic derangements are seen more frequently among the Sri Lankan population, this study was aimed to describe the metabolic derangements associated with obesity in a cohort of overweight and obese children in an urban setting of Sri Lanka.

\section{Materials and Methods}

2.1. Study Design and Setting. A cross-sectional study was conducted in the Negombo educational zone in the Gampaha district (Western province) of Sri Lanka.

2.2. Study Population. Overweight/obese (BMI for Age-SDS $\geq+1 S D$, WHO 2007) [26] 7- to 17-year-old children were identified through a separate screening programme carried out in schools in the Negombo educational zone and were invited to participate [5]. Children having a secondary cause for overweight/obesity or suffering from long-term illness or on long-term medication were excluded. 
2.3. Sample Size. Sample size was calculated to detect the expected prevalence of metabolic abnormalities in obese children. According to the findings of Wickramasinghe et al. [4], the prevalence of metabolic abnormalities among obese children was $19.2 \%$. Using this estimated prevalence, an alpha error of $5 \%$ and a margin of error of $4 \%$, the total sample required was calculated as 372 . Adding a nonresponse rate of $10 \%$, the final sample size required was determined as 409 .

2.4. Data Collection Method. By appointment, study subjects were invited to the Diabetes Screening and Vocational Training Centre of the Lions Club of Negombo Host, Negombo. Informed written consent was obtained from the parents and assent was obtained from the children. After obtaining consent, participants were given an appointment to visit the data collection center.

After a 12-hour overnight fast, children visited the center, and height, weight, and waist circumference (WC) were measured by trained research assistants using a standardized protocol [27]. The FM was assessed by Bioelectrical impedance assay (BIA) using a platform type, eight electrode InBody $230{ }^{\circledR}$ instrument (InBody ${ }^{\circledR}$, Biospace, South Korea), which had been previously validated against locally developed BIA prediction equation [28]. Blood pressure was measured manually using a mercury sphygmomanometer in the seated position after 10-15 minutes of rest. If the reading was high, it was rechecked after 15 minutes of rest and the second reading was taken.

Blood was drawn to assess fasting blood glucose (FBG), serum total cholesterol, LDL-c, HDL-c, triglyceride, insulin, alanine transaminase (ALT), aspartate transaminase (AST), and high-sensitive $\mathrm{C}$-reactive protein (Hs-CRP). Oral glucose tolerance test (OGTT) was performed after administering anhydrous glucose at the rate of $1.75 \mathrm{~g} / \mathrm{kg}$ body weight to a maximum of $75 \mathrm{~g}$ and blood was drawn 2 hours later for random blood glucose (RBG) and serum insulin. Serum was separated immediately and stored at $-20^{\circ} \mathrm{C}$ and analysis was conducted at the biochemical laboratory of the same center in batches. Blood was drawn after applying lignocane $\left(\right.$ Emla $\left.^{\circledR}\right)$ anesthetic cream. Insulin resistance was calculated using the homeostatic model (HOMA-IR = fasting blood sugar $(\mathrm{mmol} / \mathrm{L}) \times$ fasting insulin $(\mathrm{microU} / \mathrm{ml}) / 22.5)$ [29].

An experienced radiologist assessed hepatic steatosis ultrasonically. Hepatic steatosis was categorized from Grade I to III [19]. NASH was diagnosed in the presence of hepatic steatosis and elevated ALT/AST ratio of $\geq 1.0$.

Pubertal staging was assessed using visual charts [30]. Girls were shown a diagram with stages of breast and pubic hair development and were asked to match it with their own. Similarly, boys were shown diagrams of the development of different stages of external genitalia and pubic hair and were requested to match with their own. The size of the testis was measured by the examiner using a Prader orchidometer. If the subject or parents were not sure of the staging, with consent, the examiner assessed the pubertal stage for verification. Female and male investigators carried out measurements and examinations on the respective gender groups. In most of the cases, the investigators verified the results on the request of the parents.

2.5. Statistical Analysis. Standard descriptive methods, including frequencies, percentages, means, and standard deviations, were used to describe the data. Independent samples $T$ test and chi-square test were used to compare the parameters between girls and boys. Hepatic factors associated with metabolic syndrome were analysed using binary logistic regression. Mean metabolic parameters in different BMI categories were compared using one-way ANOVA test.

2.6. Definition of Metabolic Syndrome (MetS). IDF consensus definition to diagnose MetS in children was modified to suit all ages [28, 31]. Metabolic derangements were identified as: WC/Age-SDS $\geq+2$ [32]; abnormal glucose homeostasis, if $\mathrm{FBG}>5.6 \mathrm{mmol} / \mathrm{L}(100 \mathrm{mg} / \mathrm{dl})$ or 2 -hour OGTT $>7.8 \mathrm{~m}$ $\mathrm{mol} / \mathrm{L} \quad(140 \mathrm{mg} / \mathrm{dl}) ; \mathrm{HDL}<1.03 \mathrm{mmol} / \mathrm{L} \quad(<40 \mathrm{mg} / \mathrm{dl})$; triglyceride $\geq 1.7 \mathrm{mmol} / \mathrm{L} \quad(\geq 150 \mathrm{mg} / \mathrm{dl}) \quad$ [33], and SBP-SDS $\geq+2$ SD or DBP-SDS $\geq+2$ SD [34]. MetS was diagnosed in the presence of a high WC, with $2 / 4$ other criteria being elevated.

2.7. Cutoff Values for Metabolic Derangements. Fasting insulin $>83 \mathrm{pmol} / \mathrm{L}$ (12 microIU/ml) [35] and 2-hour insulin $>520 \mathrm{pmol} / \mathrm{L}$ (75 microIU/ml) [36] or HOMA-IR > 2.5 [37], $\mathrm{ALT}>40 \mathrm{IU} / \mathrm{L}, \mathrm{AST}>40 \mathrm{IU} / \mathrm{L}, \mathrm{ALT} / \mathrm{AST}$ ratio $>1.0$, and HsCRP $>3 \mathrm{mg} / \mathrm{L}$.

Data were collected from July to November 2014. Ethics approval was obtained from the Ethics Review Committee of the Faculty of Medicine, University of Colombo (EC-13143).

\section{Results}

Data of 403 (boys 210) overweight and obese children were analysed. The cohort was desegregated based on age to 7-10 years ( $n=112$, boys 61$)$ and $11-17$ years $(n=291$, boys 149$)$. Table 1 shows the distribution of the anthropometric, body composition, and metabolic parameters for each sex in each age category. Although the mean BMI SD score was not very high above the cutoff value of $+2 \mathrm{SD}$, the mean percentage fat mass was very high and girls had a significantly higher fat content than their male counterparts in each age group. Most of the parameters did not show a sex difference in the younger age group. In the older age group, girls were significantly shorter and had larger WC SD scores than boys. The mean total cholesterol levels in all four groups were above normal level but with minimum difference between groups. However, the mean HDL-c was very high in all four groups. Mean ALT was higher than the mean AST levels and both were significantly higher in boys than girls in the older age group. The mean fasting and random insulin levels were very high with high HOMA-IR levels, with no significant difference between the sexes.

Table 2 shows the distribution of abnormal anthropometric, body composition, and metabolic parameters of the population. Based on WHO BMI for Age SD score cutoff, 
TABle 1: Mean distribution of anthropometric, body composition, and metabolic parameters according to sex and age group.

\begin{tabular}{|c|c|c|c|c|c|c|}
\hline \multirow[b]{2}{*}{ Characteristics } & \multicolumn{3}{|c|}{$7-10$ years } & \multicolumn{3}{|c|}{$11-17$ years } \\
\hline & $\begin{array}{l}\text { Males }(n=61) \\
\text { Mean }(S D)\end{array}$ & $\begin{array}{c}\text { Females }(n=51) \\
\text { Mean }(\mathrm{SD})\end{array}$ & $P$ value* & $\begin{array}{l}\text { Males }(n=149) \\
\text { Mean }(S D)\end{array}$ & $\begin{array}{c}\text { Females }(n=142) \\
\text { Mean }(\mathrm{SD})\end{array}$ & $P$ value* \\
\hline Height SD score & $0.67(0.89)$ & $0.54(0.97)$ & 0.45 & $0.13(1.07)$ & $-0.24(0.89)$ & 0.002 \\
\hline BMI SD score & $2.75(0.61)$ & $2.51(0.5)$ & 0.028 & $2.37(0.48)$ & $2.31(0.38)$ & 0.254 \\
\hline WC SD score & $2.89(0.55)$ & $2.88(0.39)$ & 0.91 & $2.61(0.49)$ & $3.13(0.5)$ & $<0.001$ \\
\hline Waist/height ratio & $0.57(0.04)$ & $0.56(0.04)$ & 0.30 & $0.58(0.05)$ & $0.57(0.04)$ & 0.032 \\
\hline Percentage FM & $40.8(4.6)$ & $44.0(4.11)$ & $<0.001$ & $39.4(5.8)$ & $44.6(4.51)$ & $<0.001$ \\
\hline Systolic BP SD score & $-0.75(1.16)$ & $-0.94(0.79)$ & 0.34 & $-0.74(1.07)$ & $-0.67(1.03)$ & 0.59 \\
\hline Diastolic BP SD score & $0.83(1.09)$ & $0.69(1.03)$ & 0.49 & $1.11(1.01)$ & $1.24(0.79)$ & 0.23 \\
\hline FBS $(\mathrm{mmol} / \mathrm{L})$ & $4.83(0.49)$ & $4.82(0.51)$ & 0.94 & $4.93(0.51)$ & $4.92(0.69)$ & 0.89 \\
\hline Fasting insulin $(\mathrm{pmol} / \mathrm{L})$ & $98.62(157.65)$ & $138.21(291.0)$ & 0.38 & $128.48(204.9)$ & $115.98(164.6)$ & 0.58 \\
\hline 2-hour RBS (mmol/L) & $5.96(0.85)$ & $6.20(1.32)$ & 0.24 & $6.49(1.32)$ & $6.64(1.86)$ & 0.42 \\
\hline 2-hour insulin $(\mathrm{pmol} / \mathrm{L})$ & 368.09 (367.39) & $434.76(322.25)$ & 0.35 & $586.16(474.3)$ & $620.88(450.7)$ & 0.55 \\
\hline HOMA-IR & $3.13(5.5)$ & $4.43(10.2)$ & 0.41 & $4.04(6.1)$ & $3.64(4.9)$ & 0.57 \\
\hline Total cholesterol (mmol/L) & $5.62(0.89)$ & $5.47(1.03)$ & 0.41 & $5.41(1.12)$ & $5.56(1.18)$ & 0.27 \\
\hline Triglycerides $(\mathrm{mmol} / \mathrm{L})$ & $1.65(0.59)$ & $1.67(0.65)$ & 0.81 & $2.85(0.58)$ & $1.59(0.56)$ & 0.061 \\
\hline LDL cholesterol $(\mathrm{mmol} / \mathrm{L})$ & $3.43(0.73)$ & $3.27(0.88)$ & 0.3 & $3.30(0.97)$ & $3.43(0.95)$ & 0.25 \\
\hline HDL cholesterol $(\mathrm{mmol} / \mathrm{L})$ & $1.43(0.30)$ & $1.43(0.32)$ & 0.95 & $1.33(0.30)$ & $1.41(0.36)$ & 0.043 \\
\hline Hs-CRP (mg/L) & $1.02(0.75)$ & $1.39(0.94)$ & 0.022 & $1.12(0.88)$ & $1.02(0.78)$ & 0.28 \\
\hline $\operatorname{ALT}(\mathrm{IU} / \mathrm{L})$ & $34.6(36.9)$ & $27.6(17.1)$ & 0.22 & $33.2(22.0)$ & $23.6(19.4)$ & $<0.001$ \\
\hline AST (IU/L) & $29.5(18.7)$ & $25.9(10.8)$ & 0.23 & $26.9(11.5)$ & $21.1(9.4)$ & $<0.001$ \\
\hline
\end{tabular}

$16.4 \%$ of the study population was overweight (BMI SD +1 to $+2 \mathrm{SD}$ ), $83.6 \%$ was obese (BMI SD $>+2 \mathrm{SD}$ ), and $11.6 \%$ of the study population was severely obese (BMI SD >+3SD). Ninety-four percent had a WC above +2 SD and $95 \%$ had a $\mathrm{WHtR}>0.5$. Elevated diastolic BP was seen in $16.8 \%$ of the population, but only $2.5 \%$ had elevated systolic BP. Insulin resistance was seen in $47 \%$ and seven children had diabetes mellitus with six of them in the older age group. Elevated 2hour random insulin was seen in 35\% of children denoting that there are many who require large amounts of insulin to maintain normoglycaemia. More than a third of children under 10 years of age and half of the older children showed insulin resistance.

Although a higher number of children had elevated nonHDL lipids, only $8 \%$ showed reduced HDL-c levels. More children had elevated ALT levels than elevated AST levels, and the elevated ALT/AST ratio was seen in 58\% of the study population. About one-third of the study population had fatty livers with majority being in grade I fatty liver state. Elevated ALT and fatty liver were significantly more common in boys than in girls in the older age group.

Table 3 shows the distribution of different metabolic states according to age and sex. Dyslipidaemia was the commonest metabolic derangement (76.6\%) and dysglycaemia was seen in $20.8 \%$ while $16.8 \%$ had hypertension. MetS was seen in about $19.8 \% \%$ of this obese study group. Although MetS was seen only in about a fifth of this overweight/obese childhood and adolescent population, more than four-fifth of children had at least one abnormal metabolic component. At least one abnormal metabolic problem was seen in $84 \%$ of the population and $66.5 \%$ had at least two abnormal metabolic parameters. Therefore, only $33.5 \%$ could be considered metabolically normal obese and those having two or more abnormal metabolic parameters, were considered as unhealthy.
Table 4 shows the association between MetS and markers of nonalcoholic fatty liver disease (NAFLD). Although ALT and AST in isolation did not show any association with MetS, elevated ALT/AST ratio $(\mathrm{OR}=2.12, P=0.005)$ and hepatic steatosis $(\mathrm{OR}=1.84, P=0.015)$ were clearly associated with MetS. After adjusting for age and sex, the presence of elevated ALT/AST ratio $(\mathrm{OR}=2.17 \mathrm{CI}$, 1.25-3.77, $P=0.006)$ and having fatty liver disease (OR $=1.77, \mathrm{CI}, 1.06-2.97, P=0.029)$ continued to be significantly associated with MetS.

Table 5 shows the mean distribution of the metabolic parameters across different degrees of overweight. Liver enzymes and measures of dysglycaemia showed significant increase with worsening degrees of overweight in both groups. However, the lipids did not show any significant relationship with the degree of overweight.

\section{Discussion}

Obesity, in a majority, is an illness caused by energy imbalance, where excess energy intake and low energy expenditure leads to energy surplus, which is deposited as fat for later use. When deposition occurs beyond a critical point, it leads to obesity. The incidence of obesity is on the rise and related metabolic abnormalities are increasingly seen among younger age groups. Furthermore, these abnormal metabolic markers in childhood are shown to have extended into adulthood and predict atherosclerosis and vascular dysfunction in later life [38]. One of the main complications of obesity is the clustering of cardiovascular risk factors primarily mediated through insulin resistance, which was initially described by Gerald Reaven at the 1988 Bantin lecture. It was initially described using different nomenclatures, and finally, the term MetS was chosen [39]. 
TABle 2: Distribution of abnormal anthropometric, body composition, and metabolic parameters according to sex and age group.

\begin{tabular}{|c|c|c|c|c|c|c|}
\hline \multirow[b]{2}{*}{ Characteristics } & \multicolumn{3}{|c|}{$7-10$ years } & \multicolumn{3}{|c|}{$11-17$ years } \\
\hline & $\begin{array}{c}\text { Males }(n=61) \\
N(\%)\end{array}$ & $\begin{array}{c}\text { Females }(n=51) \\
N(\%)\end{array}$ & $P$ value* & $\begin{array}{c}\text { Males }(n=149) \\
N(\%)\end{array}$ & $\begin{array}{c}\text { Females }(n=142) \\
N(\%)\end{array}$ & $P$ value* \\
\hline Height SD score $>2$ & $6(9.8)$ & $2(3.9)$ & 0.23 & $9(6.0)$ & $2(1.4)$ & 0.038 \\
\hline $\begin{array}{l}\text { Stunting (height } \\
\text { SDS }<-2 \text { ) }\end{array}$ & $0(0.0)$ & $0(0.0)$ & - & $3(2.0)$ & $3(2.1)$ & 0.95 \\
\hline $1-2$ & $10(16.4)$ & $8(15.7)$ & & $24(16.1)$ & $24(16.9)$ & \\
\hline BMI SD score & $\begin{array}{l}31(50.8) \\
20(32.8)\end{array}$ & $\begin{array}{l}34(66.7) \\
9(17.6)\end{array}$ & 0.175 & $\begin{aligned} 112 & (75.2) \\
13 & (8.7)\end{aligned}$ & $\begin{array}{c}112(79.8) \\
6(4.2)\end{array}$ & 0.31 \\
\hline WC SD score $>2$ & $56(91.8)$ & $50(98.0)$ & 0.30 & $135(90.6)$ & $138(97.2)$ & 0.02 \\
\hline $\begin{array}{l}\text { Waist-height } \\
\text { ratio }>0.5\end{array}$ & $57(93.4)$ & $49(96.1)$ & 0.54 & $141(94.6)$ & $136(95.8)$ & 0.65 \\
\hline High percentage $\mathrm{FM}^{\mathrm{a}}$ & $61(100.0)$ & $51(100.0)$ & - & $143(96.0)$ & $142(100.0)$ & $0.03^{\#}$ \\
\hline $\begin{array}{l}\text { Systolic BP SD } \\
\text { score }>2\end{array}$ & $2(3.3)$ & $1(2.0)$ & 0.67 & $3(2.0)$ & $4(2.8)$ & 0.66 \\
\hline $\begin{array}{l}\text { Diastolic BP SD } \\
\text { score }>2\end{array}$ & $12(19.7)$ & $6(11.8)$ & 0.26 & $26(17.4)$ & $24(16.9)$ & 0.9 \\
\hline Impaired $\mathrm{FBG}^{\mathrm{b}}$ & $6(9.8)$ & $7(13.7)$ & 0.52 & $16(10.7)$ & $18(12.7)$ & $0.87^{\# \#}$ \\
\hline Impaired 2-hour $\mathrm{RBG}^{\mathrm{j}}$ & $2(3.3)$ & $3(5.9)$ & $0.43^{\#}$ & $18(12.1)$ & $21(14.8)$ & $0.69^{\# \#}$ \\
\hline Diabetes mellitus** & $0(0.0)$ & $1(2.0)$ & 0.92 & $3(2.0)$ & $3(2.1)$ & 1.0 \\
\hline $\begin{array}{l}\text { Fasting } \\
\text { insulin }>83 \mathrm{pmol} / \mathrm{L}\end{array}$ & $22(38.6)$ & $16(33.3)$ & 0.58 & $70(50.7)$ & $70(56.5)$ & 0.35 \\
\hline $\begin{array}{l}\text { 2-hour } \\
\text { Insulin }>520 \mathrm{pmol} / \mathrm{L}\end{array}$ & $13(24.1)$ & $18(40.0)$ & 0.089 & $49(37.7)$ & $61(49.2)$ & 0.064 \\
\hline High HOMA-IR ${ }^{\mathrm{k}}$ & $26(42.6)$ & $17(33.3)$ & 0.31 & $73(49.0)$ & $73(51.4)$ & 0.68 \\
\hline High total cholesterol $^{\mathrm{C}}$ & $44(72.1)$ & $28(54.9)$ & 0.058 & $81(54.4)$ & $93(65.5)$ & 0.053 \\
\hline Elevated triglycerides ${ }^{\mathrm{d}}$ & $25(41.0)$ & $18(35.3)$ & 0.54 & $67(45.0)$ & $45(31.7)$ & 0.02 \\
\hline Elevated $\mathrm{LDL}^{\mathrm{e}}$ & $33(54.1)$ & $22(43.1)$ & 0.25 & $64(43.0)$ & $74(52.1)$ & 0.12 \\
\hline Low $\mathrm{HDL}^{\mathrm{f}}$ & $5(8.2)$ & $2(3.9)$ & 0.59 & $17(11.4)$ & $9(6.3)$ & 0.13 \\
\hline Elevated Hs-CRP & $1(1.6)$ & $5(9.8)$ & 0.14 & $6(4.0)$ & $4(2.8)$ & 0.57 \\
\hline Elevated ALT $^{\mathrm{h}}$ & $12(19.7)$ & $6(11.8)$ & 0.25 & $32(21.5)$ & $15(10.6)$ & 0.011 \\
\hline Elevated $\mathrm{AST}^{\mathrm{h}}$ & $7(11.5)$ & $5(9.8)$ & 0.78 & $14(9.4)$ & $6(4.2)$ & 0.81 \\
\hline High ALT/AST ratio ${ }^{i}$ & $34(55.7)$ & $27(52.9)$ & 0.85 & $101(67.8)$ & $72(50.7)$ & 0.003 \\
\hline Fatty liver, grade I & $11(18.0)$ & $8(15.7)$ & & $39(26.2)$ & $20(14.1)$ & \\
\hline Fatty liver, grade II & $6(9.8)$ & $3(5.9)$ & 0.68 & $22(14.8)$ & $14(9.9)$ & 0.001 \\
\hline Fatty liver, grade III & $0(0.0)$ & $0(0.0)$ & & $7(4.7)$ & $1(0.7)$ & \\
\hline
\end{tabular}

${ }^{a}$ Percentage of fat mass $>28.6 \%$ in boys and $>33.7 \%$ in girls (Wickramasinghe et al.). ${ }^{b}$ Fasting blood glucose $5.6-6.9 \mathrm{mmol} / \mathrm{L} .{ }^{c}$ Total cholesterol $>5.2 \mathrm{mmol} / \mathrm{L}$. ${ }^{\mathrm{d}}$ Triglycerides $>1.7 \mathrm{mmol} / \mathrm{L}$. ${ }^{\mathrm{e}} \mathrm{LDL}$ cholesterol $>3.4 \mathrm{mmol} / \mathrm{L} .{ }^{\mathrm{f}} \mathrm{HDL}$ cholesterol $<1.03 \mathrm{mmol} / \mathrm{L}$. ${ }^{\mathrm{g}}$ High-sensitivity C-reactive protein $>3 \mathrm{mg} / \mathrm{L} .{ }^{\mathrm{h}} \mathrm{Alanine}$ transaminase (ALT) and aspartate transaminase (AST) $>40 \mathrm{IU} / \mathrm{L} .{ }^{\mathrm{i}} \mathrm{ALT} / \mathrm{AST}>1 .{ }^{\mathrm{j}}$ 2-hour random blood glucose $140-200 \mathrm{mg} / \mathrm{dL} .{ }^{\mathrm{k}} \mathrm{HOMA}$-IR $>2.5 .{ }^{* *}$ Fasting blood glucose $>6.9 \mathrm{mmol} / \mathrm{L}$ or 2-hour random blood glucose $>11.1 \mathrm{mmol} / \mathrm{L}$. ${ }^{*}$ Using Fisher's exact test. ${ }^{\# \#}$ Significance tested amalgamating IFG and DM categories. In the 7-10 years age group, 1 girl and 2 boys had both systolic and diastolic BP elevated. In the 11-17 years age group, 4 girls and 2 boys had both systolic and diastolic BP elevated. In the 11-17 years age group, 6 girls and 5 boys had both impaired FBG and impaired 2-hour RBG. In the 11-17 years age group, 1 girl had both FPG and 2-hour RBG elevated to the level of diabetes mellitus. In the 5-10 years age group, 7 girls and 6 boys had both fasting and 2hour insulin elevated. In the 11-17 years age group, 37 girls and 35 boys had both fasting and 2-hour insulin elevated. BMI: body mass index; WC: waist circumference; BP: blood pressure; FBS: fasting blood sugar; RBS: random blood sugar; HOMA-IR: homeostatic model assessment of insulin resistance; HsCRP: high-sensitivity C-reactive protein; ALT: alanine transaminase; AST: aspartate transaminase.

The overall MetS prevalence was $19.6 \%$ in this cohort and the distribution did not vary very much depending on the age. A previous study showed the prevalence of MetS to be $22.1 \%$ among obese children in the Colombo district where obesity was diagnosed based on IOTF cutoffs [4]. Eighty-five percent of the current sample had at least one metabolic abnormality. However, the prevalence of metabolic abnormalities depended on the study population and the BMI cutoff used to define them. A previous study showed all obese children to be having at least one metabolic derangement when obesity diagnosis was based on IOTF cutoff, and $43 \%$ having at least one abnormality when Sri Lankan BMI cutoffs were used [4]. The poor sensitivity of some of the international BMI cutoffs in diagnosing obesity would result in under diagnosing obesity, thus missing early stages of development of metabolic derangements [28].

A Finnish study on 2- to 17-year-old obese children showed the prevalence of hypertension and dysglycaemia to be $16.3 \%$ and $7.2 \%$, respectively. However, insulin resistance measured by HOMA-IR was 43.8\% [40]. Hypertension $(16.8 \%)$ and insulin resistance $(47 \%)$ in our study were similar; however, dysglcaemia $(20.8 \%)$ in our cohort was very high. The same study saw dyslipidaemia in 35\% but in our population, it was as high at $76 \%$. These could be due to a reflection of probably a genetic predisposition to both insulin resistance and dyslipidaemia in this South Asian population where for a given BMI value, the body fat content is higher compared to the White Caucasian populations, and 
TABLE 3: Prevalence of metabolic abnormalities according to sex and age group.

\begin{tabular}{|c|c|c|c|c|c|c|c|}
\hline \multirow{2}{*}{ Metabolic abnormality } & & \multicolumn{3}{|c|}{$7-10$ years } & \multicolumn{3}{|c|}{$11-17$ years } \\
\hline & & $\begin{array}{c}\text { Males }(n=61) \\
N(\%)\end{array}$ & $\begin{array}{c}\text { Females }(n=51) \\
N(\%)\end{array}$ & $P$ value* & $\begin{array}{c}\text { Males }(n=149) \\
N(\%)\end{array}$ & $\begin{array}{c}\text { Females }(n=142) \\
N(\%)\end{array}$ & $P$ value* \\
\hline Dysglycaemia $^{\mathrm{a}}$ & & $8(13.1)$ & $10(19.6)$ & 0.35 & $30(20.1)$ & $35(24.6)$ & 0.35 \\
\hline Dyslipidaemia $^{\mathrm{b}}$ & & $53(86.9)$ & $32(62.7)$ & 0.003 & $119(79.9)$ & $104(73.2)$ & 0.18 \\
\hline Elevated $\mathrm{BP}^{\mathrm{c}}$ & & $12(19.7)$ & $6(11.8)$ & 0.26 & $26(17.4)$ & $24(16.9)$ & 0.90 \\
\hline \multirow{3}{*}{ Metabolic syndrome ${ }^{\mathrm{d}}$} & Total & $10(16.4)$ & $8(15.7)$ & 0.91 & $38(25.5)$ & $24(16.9)$ & 0.073 \\
\hline & Overweight & $1(10.0)$ & $2(25.0)$ & 0.83 & $6(25.0)$ & $2(8.3)$ & 0.24 \\
\hline & Obese & $9(17.6)$ & $6(14.0)$ & 0.63 & $32(25.6)$ & $22(18.6)$ & 0.19 \\
\hline \multicolumn{8}{|c|}{ No. of metabolic abnormalities ${ }^{\mathrm{e}}$} \\
\hline None & & $7(11.5)$ & $13(25.5)$ & \multirow{6}{*}{$0.13^{\#}$} & $22(14.8)$ & $23(16.2)$ & \multirow{6}{*}{$0.25^{\#}$} \\
\hline 1 & & $7(11.5)$ & $7(13.7)$ & & $27(18.1)$ & $30(21.1)$ & \\
\hline 2 & & $28(45.9)$ & $14(27.5)$ & & $54(36.2)$ & $36(25.4)$ & \\
\hline 3 & & $13(21.3)$ & $12(23.5)$ & & $29(19.5)$ & $33(23.2)$ & \\
\hline 4 & & $4(6.6)$ & $5(9.8)$ & & $16(10.7)$ & $17(12.0)$ & \\
\hline 5 & & $2(3.3)$ & $0(0.0)$ & & $1(0.7)$ & $3(2.1$ & \\
\hline
\end{tabular}

${ }^{\mathrm{a}}$ Fasting blood glucose $>5.6 \mathrm{mg} / \mathrm{dL}$ or 2 -hour random blood glucose $>7.8 \mathrm{mg} / \mathrm{dL}$. ${ }^{\mathrm{b}}$ Total cholesterol $>5.2 \mathrm{mmol} / \mathrm{L}$ or $\mathrm{LDL}$ cholesterol $>3.4 \mathrm{mmol} / \mathrm{L}$ or triglycerides $>1.7 \mathrm{mmol} / \mathrm{L}$ or HDL cholesterol $<1.03 \mathrm{mmol} / \mathrm{L}$. ${ }^{\mathrm{c}}$ Systolic blood pressure and/or diastolic blood pressure $>2 \mathrm{SD}$ scores for age and sex. ${ }^{\mathrm{d}} \mathrm{W}$ aist circumference $>2$ SD scores plus 2 of the following criteria: systolic or diastolic BP elevated above 2 SD scores; serum triglycerides $>1.7 \mathrm{mmol} / \mathrm{L}$; serum HDL cholesterol < $1.03 \mathrm{mmol} / \mathrm{L}$; dysglycaemia (FBG $>5.6 \mathrm{mmol} / \mathrm{L}$ or 2 -hour RBG $>7.8 \mathrm{mmol} / \mathrm{L}$ ). ${ }^{\mathrm{e}}$ Number of metabolic abnormalities out of elevated BP (systolic or diastolic $\mathrm{BP}>2 \mathrm{SDS}$ ), dysglycaemia (FBG $>5.6 \mathrm{mmol} / \mathrm{L}$ or 2-hour $\mathrm{RBG}>7.8 \mathrm{mmol} / \mathrm{L}$ ), elevated total cholesterol $(>5.2 \mathrm{mmol} / \mathrm{L})$, elevated $\mathrm{LDL}$ $(>13.4 \mathrm{mmol} / \mathrm{L})$, elevated triglycerides $(>1.7 \mathrm{mmol} / \mathrm{L})$, low $\mathrm{HDL}(<1.03 \mathrm{mmol} / \mathrm{L})$, and elevated $\mathrm{Hs}-\mathrm{CRP}(>3 \mathrm{mg} / \mathrm{L}) .{ }^{*} P$ value calculated using chi-square test. ${ }^{\#}$ Statistical significance was calculated after amalgamating $3,4,5$, and 6 metabolic abnormalities in order to account for small values in cells.

TABLE 4: Association between the presence of metabolic syndrome and liver abnormalities $(n=403)$.

\begin{tabular}{|c|c|c|c|c|c|}
\hline \multicolumn{6}{|c|}{ Metabolic syndrome } \\
\hline \multicolumn{2}{|c|}{ Liver abnormalities } & \multirow{2}{*}{$\begin{array}{c}\text { Absent }(n=323) \\
N(\%) \\
275(81.6)\end{array}$} & \multirow{2}{*}{$\begin{array}{c}\text { Present }(n=80) \\
N(\%) \\
62(18.3)\end{array}$} & \multirow{3}{*}{$\begin{array}{l}\text { OR }(95 \% \mathrm{CI}) \text { significance* } \\
\begin{array}{c}1.71(0.93-3.14) \\
P=0.084\end{array}\end{array}$} & \multirow{3}{*}{$\begin{array}{c}\text { Adjusted OR (95\% CI) significance }{ }^{* *} \\
1.73(0.94-3.21) ; \\
P=0.079\end{array}$} \\
\hline AIT & Normal & & & & \\
\hline ALI & High & $47(72.3)$ & $18(27.7)$ & & \\
\hline \multirow{2}{*}{ AST } & Normal & $299(80.8)$ & $71(19.1)$ & $1.65(0.73-3.7)$ & 2.03 (0.9-4.57); \\
\hline & High & $23(71.9)$ & $9(28.1)$ & $P=0.22$ & $P=0.088$ \\
\hline \multirow{2}{*}{ ALT/AST } & Normal & $147(87.5)$ & $21(12.5)$ & $2.12(1.25-3.61)$ & $2.17(1.25-3.77)$ \\
\hline & High & $175(74.8)$ & $59(25.2)$ & $\mathbf{P}=0.005$ & $\mathbf{P}=0.006$ \\
\hline \multirow{2}{*}{ Fatty liver } & Absent & $226(83.7)$ & $44(16.3)$ & $1.84(1.12-3.04)$ & 1.77 (1.06-2.97); \\
\hline & Present & $96(73.3)$ & $35(26.7)$ & $\mathrm{P}=\mathbf{0 . 0 1 5}$ & $\mathrm{P}=0.029$ \\
\hline \multirow{2}{*}{$\mathrm{NASH}^{\mathrm{a}}$} & Absent & $243(82.9)$ & $50(17.1)$ & $1.73(1.02-2.9)$ & $1.15(1.02-2.72)$ \\
\hline & Present & $78(72.9)$ & $29(27.1)$ & $P=0.039$ & $P=0.093$ \\
\hline
\end{tabular}

AST: aspartate transaminase; ALT: alanine transaminase. ${ }^{*}$ Using chi-square test. ${ }^{a} \mathrm{NASH}$ : nonalcoholic steatohepatitis is diagnosed in the presence of the fatty liver with elevated ALT/AST. ${ }^{* *}$ Using binary logistic regression with the presence of metabolic syndrome as the dependent variable and adjusting for age and sex. Data missing in $n=1$ for AST and ALT, $n=2$ for the fatty liver, and $n=3$ for NASH.

most of the body fat in Asians is deposited in the abdomen $[7,41]$.

Two to six-year-old children in the same Finish study showed a high WC in $85.1 \%$, dyslipidaemia in $20.6 \%$, hypertension in $5.9 \%$, and IFG or IGT in $3.8 \%$. A fifth of the population (19.8\%) had abnormal HOMA showing a high amount of insulin resistance at such a young age [40]. Although we did not study such a younger age group, the younger population in our study, 7- to 10-year-old children, showed a very high prevalence of metabolic abnormalities compared to this younger Finish cohort, which could expect to match or even surpass if we would have studied a similar younger population.

A Polish study involving 6-, 10-, and 14-year-old overweight and obese children found that $38.2 \%$ of girls and $40.5 \%$ of boys with overweight and obesity were having at least one lipid abnormality. The most common lipid disorders that were observed were decreased HDL-c $(20.6 \%$ of the girls and $23.8 \%$ of the boys) and elevated LDL-c (15.3\% of the girls and $14.3 \%$ of the boys) [42]. Abnormal triglyceride was observed in a minority of children $(6.0 \%$ of the girls and $8.8 \%$ of the boys). Those with dyslipidaemia were significantly older, had higher BMI, WC, and body fat than those without dyslipidaemia [42]. However, in our population, low HDL-c levels were less than ten percent but other lipid abnormalities were seen in more than a third to half of the study population.

Prevalence of MetS ranged from $15 \%$ to $25 \%$ in the different age and sex groups in the current study. A study in France involving 7- to 15-year-olds showed MetS to be $18.6 \%$ in children below 10 years of age and $14.5 \%$ among 10 - to 15-year-old children according to the National 
TABLE 5: Patterns of metabolic parameters according to the BMI category.

\begin{tabular}{|c|c|c|c|c|c|}
\hline Metabolic parameters & $\begin{array}{c}\text { BMI SDS } 1-2(n=66) \\
\text { Mean }(S D)\end{array}$ & $\begin{array}{c}\text { BMI SDS 2-3 }(n=289) \\
\text { Mean }(\mathrm{SD})\end{array}$ & $\begin{array}{c}\text { BMI SDS }>3(n=48) \\
\text { Mean }(S D)\end{array}$ & Significance* & $\begin{array}{c}\text { Groups with significant } \\
\text { difference }\end{array}$ \\
\hline \multicolumn{6}{|l|}{ Females } \\
\hline FBG $(\mathrm{mmol} / \mathrm{L})$ & $4.81(0.52)$ & $4.92(0.68)$ & $4.76(0.59)$ & 0.49 & - \\
\hline Fasting insulin $(\mathrm{pmol} / \mathrm{L})$ & $97.23(77.09)$ & $126.40(229.19)$ & $90.28(65.28)$ & 0.70 & - \\
\hline 2-hour RBS (mmol/L) & $6.05(1.05)$ & $6.60(1.83)$ & $6.27(1.35)$ & 0.23 & - \\
\hline 2-hour insulin (pmol/L) & $476.43(295.86)$ & $587.55(437.54)$ & $517.40(329.89)$ & 0.41 & - \\
\hline HOMA-IR & $3.08(2.5)$ & $4.2(7.5)$ & $2.73(2.1)$ & 0.69 & - \\
\hline Total cholesterol (mmol/L) & $5.50(1.29)$ & $5.52(1.12)$ & $5.80(1.15)$ & 0.65 & - \\
\hline Triglycerides $(\mathrm{mmol} / \mathrm{L})$ & $1.64(0.73)$ & $1.64(0.56)$ & $1.34(0.37)$ & 0.15 & - \\
\hline LDL cholesterol (mmol/L) & $3.36(0.97)$ & $3.36(0.93)$ & $3.72(0.85)$ & 0.35 & - \\
\hline HDL cholesterol (mmol/L) & $1.39(0.31)$ & $1.41(0.36)$ & $1.47(0.37)$ & 0.78 & - \\
\hline Hs-CRP (mg/L) & $0.92(0.64)$ & $1.1(0.82)$ & $1.5(1.03)$ & 0.064 & - \\
\hline $\operatorname{ALT}(\mathrm{IU} / \mathrm{L})$ & $19.5(10.6)$ & $24.3(19.3)$ & $37.5(23.6)$ & 0.009 & $1-2$ and $>3,2-3$ and $>3$ \\
\hline AST (IU/L) & $19.5(6.2)$ & $22.2(10.0)$ & $28.6(13.8)$ & 0.014 & $1-2$ and $>3$ \\
\hline ALT/AST ratio & $0.98(0.27)$ & $1.05(0.31)$ & $1.25(0.36)$ & 0.023 & $1-2$ and $>3,2-3$ and $>3$ \\
\hline Percentage fat mass & $40.3(4.01)$ & $44.83(3.8)$ & $49.85(3.21)$ & $<0.001$ & All 3 from each other \\
\hline \multicolumn{6}{|l|}{ Males } \\
\hline FBG (nmol/L) & $4.86(0.51)$ & $4.92(0.53)$ & $4.91(0.42)$ & 0.82 & - \\
\hline Fasting insulin $(\mathrm{pmol} / \mathrm{L})$ & $81.95(71.53)$ & $118.06(182.65)$ & $165.29(293.77)$ & 0.22 & - \\
\hline 2-hour RBS $(\mathrm{nmol} / \mathrm{L})$ & $5.84(0.77)$ & $6.40(1.28)$ & $6.65(1.27)$ & 0.021 & $1-2$ and $>3$ \\
\hline 2-hour insulin $(\mathrm{pmol} / \mathrm{L})$ & $379.89(377.11)$ & $515.32(432.67)$ & $697.97(563.24)$ & 0.023 & $1-2$ and $>3$ \\
\hline HOMA-IR & $2.55(2.1)$ & $3.68(5.3)$ & $5.39(9.9)$ & 0.16 & - \\
\hline Total cholesterol (mmol/L) & $5.57(1.23)$ & $5.43(1.03)$ & $5.47(1.06)$ & 0.73 & - \\
\hline Triglycerides $(\mathrm{mmol} / \mathrm{L})$ & $1.73(0.68)$ & $1.69(0.55)$ & $1.71(0.61)$ & 0.94 & - \\
\hline LDL cholesterol (mmol/L) & $3.29(1.05)$ & $3.33(0.88)$ & $3.40(0.92)$ & 0.89 & - \\
\hline HDL cholesterol (mmol/L) & $1.48(0.37)$ & $1.33(0.28)$ & $1.35(0.24)$ & 0.024 & $1-2$ and $2-3$ \\
\hline $\mathrm{Hs}-\mathrm{CRP}(\mathrm{mg} / \mathrm{L})$ & $0.83(0.72)$ & $1.1(0.86)$ & $1.4(0.82)$ & 0.022 & $1-2$ and $>3$ \\
\hline $\operatorname{ALT}(\mathrm{IU} / \mathrm{L})$ & $25.7(19.3)$ & $33.2(21.6)$ & $43.1(47.6)$ & 0.034 & $1-2$ and $>3$ \\
\hline AST (IU/L) & $26.5(13.6)$ & $27.5(11.7)$ & $29.3(22.1)$ & 0.71 & - \\
\hline ALT/AST ratio & $0.95(0.32)$ & $1.18(0.38)$ & $1.40(0.54)$ & $<0.001$ & All 3 from each other \\
\hline Percentage fat mass & $34.45(5.06)$ & $39.78(4.56)$ & $45.55(4.09)$ & $<0.001$ & All 3 from each other \\
\hline
\end{tabular}

* Statistical significance was assessed using one-way ANOVA test, and the pairwise comparisons were made using the Bonferroni method.

Cholesterol Education Program (NCEP) Adult Treatment Panel III [43]. Based on IDF consensus definition, in 10- to 15-year-old children, the prevalence of MetS was $8.9 \%$. Although there is still no consensus on the diagnostic criteria of MetS in children, it is quite evident that children with MetS pose a higher risk of developing MetS as adults. The Princeton prevalence and follow-up study has showed that childhood MetS has an odds ratio of 9.4 to develop MetS and 11.2 to develop diabetes mellitus as an adult [44]. For adults with MetS, the hazard ratio to develop coronary heart disease mortality was 2.87 and it was 5.02 for diabetes mellitus mortality [45].

Components of MetS such as obesity, insulin resistance, hypertension, and dyslipidaemia are seen to be clustered in black and white children and adults in Bogalusa, USA [38]. These results suggest that the MetS components coexist, not only in terms of absolute levels in childhood and adulthood but also in terms of rates of change from childhood to adulthood. This has shown the importance of obesity in the development of MetS in all ages, thus showing that maintaining a proper BMI from early life is of paramount importance in the prevention of obesity and related complications [38].

Data in our study quite clearly show that cardio metabolic risks and MetS are present in children as young as 7-10 years of age. Since evidence points out that obesity and metabolic complications persist into adulthood, early diagnosis and treatment of MetS and other metabolic abnormalities during childhood is important. Although there is lack of consensus on the definition of MetS in children, the American Diabetes Association and American Heart Association highlight that extra vigilance in detection of insulin resistance, glucose intolerance, and type 2 diabetes early in the course of development would lead to effective early interventions, thus preventing progression into complications [46]. Current knowledge shows that better glycaemic control would lead to better long-term microvascular and macrovascular outcomes, which are the prime factors that determine long-term outcomes of diabetes mellitus. Therefore, the best preventive approach for future cardiovascular disease is early recognition and aggressive intervention. Without this, it is likely that this patient population is destined to develop cardiovascular complications at a younger age in epidemic proportions [46].

The IDF consensus definition did not recommend to entertain a diagnosis of metabolic syndrome in children younger than 10 years of age due to lack of evidence [31]. However, it needs to be highlighted that this definition is now more than 14 years old and a dearth of evidence has been generated thereafter $[4,11,40,42]$. The South Asian 
region where insulin resistance and CVRF are highly prevalent has produced lot of data on the magnitude of the problem of childhood obesity and related metabolic derangements $[8,37]$. Therefore, in order to facilitate awareness and early intervention, it is important to make the diagnosis of MetS early in life.

Sex and pubertal status influences the occurrence of CVRF in children with obesity [40]. Different CVRFs predominate in both the genders differently with more insulin resistance seen in females and hypertension, abdominal obesity, and dysplipdaemia in males, and further risk factors were seen in prepubertal age as well [40]. However, in our study, no significant sex difference was noted for metabolic derangements except for the fat content where females had a higher amount of body fat compared to their male counterparts, especially abdominal fat in the older age group, denoted by the high WC, $\mathrm{SD}$, and WHtR. Pubertal status did not show significant influence on the occurrence of metabolic abnormalities with prepubertal children also having high prevalence of metabolic derangements and MetS in our study (data not shown). The mechanism underlying the sex differences in CVRF is not clearly understood but a multitude of factors could be affecting where genetics could be playing a major role. In our data, we do not see a clear relationship of lipid abnormalities with the degree of overweight as well as with sex, but insulin resistance and related metabolic abnormalities including liver damage increased with the worsening degree of overweight as well as with increasing age. This probably could shed some light on the fact that genetics of obesity (or insulin resistance) and lipid metabolism could act in harmony to develop metabolic derangements in children [25]. Therefore, probably in this South Asian population, a multitude of factors such as hormone milieu driven by fat content, genetics determining regional body composition, obesity, and lipid metabolism could be playing a role in developing metabolic abnormalities of a higher magnitude at a younger age.

The purpose of screening for NAFLD in children and adolescents is to prevent irreversible, end-stage liver disease. The exponential rise in childhood overweight/ obesity has made NAFLD one of the most important causes of chronic liver disease [47] However, NAFLD in children is still underdiagnosed mainly due to poor awareness, recognition, and due to the absence of a proper validated diagnostic tool $[48,49]$. White Caucasians and Asian children have high prevalence compared to African American children, and NAFLD is also more prevalent in male children than female children $[48,50,51]$. Based on a meta-analysis of evidence from studies conducted in paediatric obesity clinics, the prevalence of NAFLD among children and adolescents was $34.2 \%$ [52]. In our population of overweight and obese children, prevalence of NAFLD was $32.5 \%$ and that of NASH was $26.5 \%$, which are similarly high. With age, children are more likely to have complications of NAFLD and there is an urgent need to develop robust screening tools for early detection in high-risk groups [49].

\section{Conclusions}

This study clearly shows that cardiovascular metabolic risk, MetS, NAFLD and NASH are prevalent among obese Sri Lankan children starting from a very young age. This warrants active screening of the child population for obesity and assessing for both cardiovascular and hepatic metabolic complications actively in order to prevent the progression of obesity-related metabolic derangements into adulthood and to curb the ever-increasing rates of NCD in the world. Furthermore, reaching a consensus on diagnostic techniques for obesity and MetS and creating awareness about these conditions among the medical fraternity as well as the general public is of paramount importance and urgency.

\section{Data Availability}

The data used to support the findings of this study are available from the corresponding author upon request.

\section{Disclosure}

This study was presented in part using a different analysis technique, in the abstract form, at local academic sessions. Loretta S. Warnakulasuriya and Dulani L. Samaranayake are joint first authors.

\section{Conflicts of Interest}

The authors declare no conflicts of interest.

\section{Authors' Contributions}

VPW, LSW, and ER conceived the research idea. LSW, MAMF, AVNA, KDRRS, ER, DLS, and VPW designed the study protocol and executed the same. LSW, MAMF, AVNA, ARMT, WMLA, and MSFS conducted the study. DLS analysed the data. VPW, DLS, and AHF wrote the paper. All authors gave the final approval of the submitted and published versions.

\section{Acknowledgments}

The authors thank all the children and their parents/ guardians for participating in this study. They also thank Dr. B.K.T.P. Dayanath, Consultant Chemical Pathologist, for supervising the function of the laboratory, Dr. Sumudu Palihawadana, Consultant Radiologist, for carrying out the ultrasound examination of the abdomen for hepatic steatosis, Mr. M. Sheran Weerasinghe for managing the entire project, and the following members of the research team in conducting the study: Dr. TMCLB Thennakoon, Dr. C Jayalath, Dr. GLDL Pradeepani, Dr. AVNC Adikaram, Dr. LDAC Arawwawala, Dr. NS Jayasinghe, Ms. SANM Fernando, Ms. RRM S Sewwandhi, Ms HAI Sandamali, Ms. WC Kumari, Ms. BLS Prasadini, Mr. RSR Ranathunga, Mr. TL Kanth, Ms. NY Watawala, Ms. KBG S Sankalpani, Ms. S Silva Antonypulle, Ms SNI Fernando, Mr. WG Thusith, and Ms. SUS Fernando. This study was funded by an educational 
grant from Swedish Radiohjälpen, "Children of the World," to Lions Club Negombo Host, Negombo, Sri Lanka.

\section{References}

[1] NCD Risk Factor Collaboration, "Worldwide trends in bodymass index, underweight, overweight, and obesity from 1975 to 2016: a pooled analysis of 2416 population-based measurement studies in 128.9 million children, adolescents, and adults," Lancet, vol. 390, no. 10113, pp. 2627-2642, 2017.

[2] G. B. D. O. Collaborators, A. Afshin, M. H. Forouzanfar et al., "Health effects of overweight and obesity in 195 countries over 25 years," New England Journal of Medicine, vol. 377, no. 1, pp. 13-27, 2017.

[3] V. P. Wickramasinghe, S. P. Lamabadusuriya, N. Atapattu, G. Sathyadas, S. Kuruparanantha, and P. Karunarathne, "Nutritional status of schoolchildren in an urban area of Sri Lanka," The Ceylon Medical Journal, vol. 49, no. 4, pp. 114-118, 2004.

[4] V. P. Wickramasinghe, C. Arambepola, P. Bandara et al., "Distribution of obesity-related metabolic markers among 5-15 year old children from an urban area of Sri Lanka," Annals of Human Biology, vol. 40, no. 2, pp. 168-174, 2013.

[5] L. S. Warnakulasuriya, M. A. M. Fernando, A. V. N. Adikaram et al., "Assessment of nutritional status in Sri Lankan children: validity of current anthropometry cutoffs?" Asia Pacific Journal of Public Health, vol. 31, no. 7, pp. 633-642, 2019.

[6] S. E. Litwin, "Childhood obesity and adulthood cardiovascular disease," Journal of the American College of Cardiology, vol. 64, no. 15, pp. 1588-1590, 2014.

[7] V. P. Wickramasinghe, G. J. Cleghorn, K. A. Edmiston, A. J. Murphy, R. A. Abbott, and P. S. W. Davies, "Validity of BMI as a measure of obesity in Australian white Caucasian and Australian Sri Lankan children," Annals of Human Biology, vol. 32, no. 1, pp. 60-71, 2005.

[8] V. P. Wickramasinghe, C. Arambepola, P. Bandara et al., "Insulin resistance in a cohort of 5-15 year old children in urban Sri Lanka," BMC Research Notes, vol. 10, no. 1, p. 347, 2017.

[9] V. Calcaterra, C. Klersy, T. Muratori et al., "Prevalence of metabolic syndrome (MS) in children and adolescents with varying degrees of obesity," Clinical Endocrinology, vol. 68, no. 6, pp. 868-872, 2008.

[10] L. J. Griffiths, T. J. Parsons, and A. J. Hill, "Self-esteem and quality of life in obese children and adolescents: a systematic review," International Journal of Pediatric Obesity, vol. 5, no. 4, pp. 282-304, 2010.

[11] M. F. Faienza, M. Chiarito, E. Molina-Molina et al., "Childhood obesity, cardiovascular and liver health: a growing epidemic with age," World Journal of Pediatrics, vol. 16, no. 5, pp. 438-445, 2020.

[12] D. S. Freedman, Z. Mei, S. R. Srinivasan, G. S. Berenson, and W. H. Dietz, "Cardiovascular risk factors and excess adiposity among overweight children and adolescents: the Bogalusa Heart Study," The Journal of Pediatrics, vol. 150, no. 1, pp. 12-17, 2007.

[13] D. R. Mager and E. A. Roberts, "Nonalcoholic fatty liver disease in children," Clinics in Liver Disease, vol. 10, no. 1, pp. 109-131, 2006.

[14] K. Widhalm and E. Ghods, "Nonalcoholic fatty liver disease: a challenge for pediatricians," International Journal of Obesity, vol. 34, no. 10, pp. 1451-1467, 2010.

[15] K. Nanda, "Non-alcoholic steatohepatitis in children," Pediatric Transplantation, vol. 8, no. 6, pp. 613-618, 2004.
[16] K. S. de Silva, V. P. Wickramasinghe, and I. N. Gooneratne, "Metabolic consequences of childhood obesity--a preliminary report," The Ceylon Medical Journal, vol. 51, no. 3, pp. 105-109, 2006.

[17] P. Portincasa, I. Grattagliano, V. O. Palmieri, and G. Palasciano, "The emerging problem of nonalcoholic steatohepatitis (NASH)," Romanian Journal of Gastroenterology, vol. 14, no. 1, pp. 43-51, 2005.

[18] R. M. L. De Bruyne, E. Fitzpatrick, and A. Dhawan, "Fatty liver disease in children: eat now pay later," Hepatology International, vol. 4, no. 1, pp. 375-385, 2010.

[19] A. Shannon, N. Alkhouri, C. Carter-Kent et al., "Ultrasonographic quantitative estimation of hepatic steatosis in children with NAFLD," Journal of Pediatric Gastroenterology \& Nutrition, vol. 53, no. 2, pp. 190-195, 2011.

[20] A. B. Mjelle, A. Mulabecirovic, R. F. Havre et al., "Normal liver stiffness values in children: a comparison of three different elastography methods," Journal of Pediatric Gastroenterology \& Nutrition, vol. 68, no. 5, pp. 706-712, 2019.

[21] J. H. Runge, J. van Giessen, L. G. Draijer et al., "Accuracy of controlled attenuation parameter compared with ultrasound for detecting hepatic steatosis in children with severe obesity," European Radiology, vol. 31, no. 3, pp. 1588-1596, 2021.

[22] I. B. Maier, Y. Özel, A. J. Engstler et al., "Differences in the prevalence of metabolic disorders between prepubertal boys and girls from 5 to 8 years of age," Acta Paediatrica, vol. 103, no. 4, pp. e154-e160, 2014.

[23] F. Mauvais-Jarvis, "Sex differences in metabolic homeostasis, diabetes, and obesity," Biology of Sex Differences, vol. 6, no. 1, p. 14, 2015.

[24] J. C. Link, X. Chen, A. P. Arnold, and K. Reue, "Metabolic impact of sex chromosomes," Adipocyte, vol. 2, no. 2, pp. 74-79, 2013.

[25] R. Nagrani, R. Foraita, F. Gianfagna et al., "Common genetic variation in obesity, lipid transfer genes and risk of metabolic syndrome: results from IDEFICS/I.Family study and metaanalysis," Scientific Reports, vol. 10, no. 1, p. 7189, 2020.

[26] M. de Onis, A. W. Onyango, E. Borghi, A. Siyam, C. Nishida, and J. Siekmann, "Development of a WHO growth reference for school-aged children and adolescents," Bull World Health Organ, vol. 85, no. 9, pp. 660-667, 2007.

[27] T. G. Lohman, "Assessment of body composition in children," Pediatric Exercise Science, vol. 1, p. 12, 1989.

[28] V. P. Wickramasinghe, C. Arambepola, D. M. P. S. Bandara et al., "Validity of newly-developed BMI and waist cut-off values for Sri Lankan children," Annals of Human Biology, vol. 40, no. 3, pp. 280-285, 2013.

[29] D. R. Matthews, J. P. Hosker, A. S. Rudenski, B. A. Naylor, D. F. Treacher, and R. C. Turner, "Homeostasis model assessment: insulin resistance and ?-cell function from fasting plasma glucose and insulin concentrations in man," Diabetologia, vol. 28, no. 7, pp. 412-419, 1985.

[30] N. M. Morris and J. R. Udry, "Validation of a self-administered instrument to assess stage of adolescent development," Journal of Youth and Adolescence, vol. 9, no. 3, pp. 271-280, 1980.

[31] P. Zimmet, K. G. M. Alberti, F. Kaufman et al., "The metabolic syndrome in children and adolescents ? an IDF consensus report," Pediatric Diabetes, vol. 8, no. 5, pp. 299-306, 2007.

[32] H. McCarthy, K. Jarrett, and H. Crawley, "The development of waist circumference percentiles in British children aged 5.016.9 y," European Journal of Clinical Nutrition, vol. 55, no. 10, pp. 902-907, 2001.

[33] P. Zimmet, G. Alberti, F. Kaufman et al., "The metabolic syndrome in children and adolescents," The Lancet, vol. 369, no. 9579, pp. 2059-2061, 2007. 
[34] L. V. Jackson, N. K. S. Thalange, and T. J. Cole, "Blood pressure centiles for great britain," Archives of Disease in Childhood, vol. 92, no. 4, pp. 298-303, 2007.

[35] L. M. Hettihawa, S. Palangasinghe, S. S. Jayasinghe, S. W. Gunasekara, and T. P. Weerarathna, "Comparison of insulin resistance by indirect methods-HOMA, QUICKI and McAuley - with fasting insulin in patients with type 2 diabetes in Galle, Sri Lanka: a pilot study," Online Journal of Health and Allied Sciences, vol. 1, p. 1, 2006.

[36] S. Ten and N. Maclaren, "Insulin resistance syndrome in children," The Journal of Clinical Endocrinology \& Metabolism, vol. 89, no. 6, pp. 2526-2539, 2004.

[37] Y. Singh, M. K. Garg, N. Tandon, and R. K. Marwaha, "A study of insulin resistance by HOMA-IR and its cut-off value to identify metabolic syndrome in urban Indian adolescents," Journal of Clinical Research in Pediatric Endocrinology, vol. 5, no. 4, pp. 245-251, 2013.

[38] W. Chen, S. R. Srinivasan, S. Li, J. Xu, and G. S. Berenson, "Clustering of long-term trends in metabolic syndrome variables from childhood to adulthood in Blacks and Whites: the Bogalusa Heart Study," American Journal of Epidemiology, vol. 166, no. 5, pp. 527-533, 2007.

[39] G. M. Reaven, "Banting lecture 1988. Role of insulin resistance in human disease," Diabetes, vol. 37, no. 12, pp. 1595-1607, 1988.

[40] C. Guzzetti, A. Ibba, L. Casula, S. Pilia, S. Casano, and S. Loche, "Cardiovascular risk factors in children and adolescents with obesity: sex-related differences and effect of puberty," Frontiers in Endocrinology, vol. 10, p. 591, 2019.

[41] V. P. Wickramasinghe, C. Arambepola, P. Bandara et al., "Use of Waist to Height Ratio in assessing metabolic derangements among normal and overweight/obese 5-15 year old individuals," Ceylon Journal of Medical Science, vol. 54, no. 1, p. 9, 2017.

[42] M. Brzezinski, P. Metelska, M. Mysliwiec, and A. SzlagatysSidorkiewicz, "Lipid disorders in children living with overweight and obesity- large cohort study from Poland," Lipids in Health and Disease, vol. 19, no. 1, p. 47, 2020.

[43] C. Druet, K. Ong, and C. Levy Marchal, "Metabolic syndrome in children: comparison of the International Diabetes Federation 2007 consensus with an adapted National Cholesterol Education Program definition in 300 overweight and obese French children," Hormone Research in Paediatrics, vol. 73, no. 3, pp. 181-186, 2010.

[44] J. A. Morrison, L. A. Friedman, P. Wang, and C. J. Glueck, "Metabolic syndrome in childhood predicts adult metabolic syndrome and type 2 diabetes mellitus 25 to 30 years later," The Journal of Pediatrics, vol. 152, no. 2, pp. 201-206, 2008.

[45] S. Malik, N. D. Wong, S. S. Franklin et al., "Impact of the metabolic syndrome on mortality from coronary heart disease, cardiovascular disease, and all causes in United States adults," Circulation, vol. 110, no. 10, pp. 1245-1250, 2004.

[46] J. Steinberger and S. R. Daniels, "Obesity, insulin resistance, diabetes, and cardiovascular risk in children," Circulation, vol. 107, no. 10, pp. 1448-1453, 2003.

[47] Z. Younossi, Q. M. Anstee, M. Marietti et al., "Global burden of NAFLD and NASH: trends, predictions, risk factors and prevention," Nature Reviews Gastroenterology \& Hepatology, vol. 15, no. 1, pp. 11-20, 2018.

[48] S. K. Smith and E. R. Perito, "Nonalcoholic liver disease in children and adolescents," Clinics in Liver Disease, vol. 22, no. 4, pp. 723-733, 2018.

[49] L. Draijer, M. Benninga, and B. Koot, "Pediatric NAFLD: an overview and recent developments in diagnostics and treatment," Expert Review of Gastroenterology \& Hepatology, vol. 13, no. 5, pp. 447-461, 2019.

[50] J. B. Schwimmer, R. Deutsch, T. Kahen, J. E. Lavine, C. Stanley, and C. Behling, "Prevalence of fatty liver in children and adolescents," Pediatrics, vol. 118, no. 4, pp. 1388-1393, 2006.

[51] S. Wiegand, K. M. Keller, K.-M. Keller et al., "Obese boys at increased risk for nonalcoholic liver disease: evaluation of 16 390 overweight or obese children and adolescents," International Journal of Obesity, vol. 34, no. 10, pp. 1468-1474, 2010.

[52] E. L. Anderson, L. D. Howe, H. E. Jones, J. P. T. Higgins, D. A. Lawlor, and A. Fraser, "The prevalence of non-alcoholic fatty liver disease in children and adolescents: a systematic review and meta-analysis," PLoS One, vol. 10, no. 10, Article ID e0140908, 2015. 